\title{
Unstoppable: A critical reflection on the socio-economic embeddedness of technology and the implications for the human agenda
}

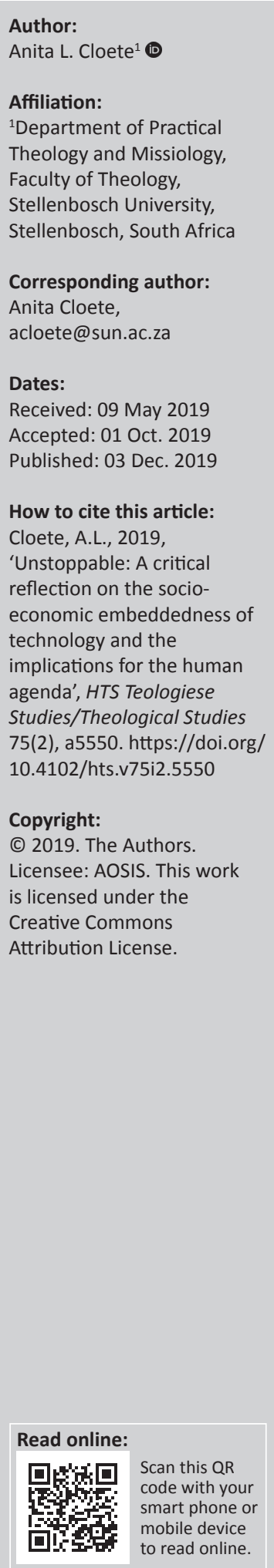

The overall aim of the article is to unpack some of the layers of motivation that inform and shape the relationship between technology and education. This aim is motivated by the need for a more nuanced perspective on the complex relationship between technology and education. The discussion of technology and education would be utilised as springboard to provide a platform for elaborating on the complex nature of technology as medium, its broader impact on society and the kind of life it creates. The article names a few of the external and internal imperatives for the integration of technology into education. The first part of the title refers to the name of a film about an unmanned, runaway train with serious consequences for the environment and humanity at large. The idea is to relate the pervasive, self-enforcing nature and role of technology with the theme of the film, a force that seems to be unstoppable. It is argued that the integration of technology into education cannot be reflected in isolation from an understanding of the complex nature of technology and the broader functioning of technology in other spheres of life. The socio-economic embeddedness of technology is unpacked by discussing the mediatisation theory, technological development as a revolution and the Fourth Industrial Revolution. The final section describes the need for and possible processes to sharpen the focus on ethics in digital age.

Keywords: technology; education; Fourth Industrial Revolution; ethics; mediatisation.

\section{Introduction}

Nobody can absorb all the latest scientific discoveries... nobody has a clue where we are heading in such a rush. Since no one understands the system any more, no one can stop it. (Harari 2016:59)

The first section presents a few motivations for the use of technology in education, followed by three examples on the use of educational technologies in the classroom. The outcome or results of these examples are being underscored, pointing out the complexity regarding the mediation of learning and utilising educational technologies. The second section unpacks the socio-economic embeddedness of technology by discussing at least three theories that in different ways highlight the invasive nature of technology and its impact on people and society. The third section pays special attention to values and technology by dissecting the dynamic relationship between the values that are embedded in technology by design and that of users thereof and how these values are interlinked.

\section{Education and technology}

The opening statement of Selwyn (2011:1) in his book Education and Technology: Key Issues and Debates is appropriate for this discussion.

He states: 'Educational technology is a topic that is often talked about, but less often thought about'. Precisely for this reason there is little to no critical reflection on the medium of educational technology because educators think they should simply get on with it and use it. I wish to argue that this is a key oversight, because continuous critical reflection is needed on the complexity of technology in order to design and use it in ways that are in the interest of common good.

It is helpful to at least put forward a working definition of how technology can be understood, because often our understanding thereof is reduced to tools, machines or gadgets to be used as we find fit. This is not only a simplistic view but also a misleading one. Technology is not new, but has existed since people first converted natural resources into tools. But it is the accelerated

Note: This article is published in the section Practical Theology of the Society for Practical Theology in South Africa. 
pace at which very sophisticated technology is developing that makes it a game changer around the globe today. The need and use of these tools can be associated with emotional needs such as decoration and adornment. 'Digital technologies are associated with dramatically enhanced and improved ways of doing things' (Selwyn 2011:12). Therefore one of the outstanding beliefs about and attitudes towards technology is that it would enhance and improve current forms of living as it includes certain skills and knowledge (Selwyn 2011:7). It is important to keep in mind that technology encompasses much more than devices, and also entails practices and broader contexts, including institutions, social structures and cultures (Selwyn 2011:8). Technology is not only what we could see and touch (tangible things), but also what we dream and desire for (Cloete 2017:2). It is therefore paramount to plot any discussion on technology as part of a broader framework of culture.

One of the most common driving forces behind the use of technology in education is simply the imperative to keep up with the changes and opportunities in society. We feel we should participate in the good life created and promised by technology. Therefore, phrases such as 'staying relevant' are often used to describe why education is in need of technology (Cloete 2017:2). Another primary motivation is that the knowledge economy is biased towards technological skills. This literally means that the economy is structured and functions in such a way that it is biased towards people who have technological skills. Therefore, pressure to use technology in education originates not only from the business and government sectors but also from students and parents who believe that technology would enhance their quality of education and opportunities for employment (Selwyn 2011:23). The instalment and use of educational technologies in educational institutions are also perceived to create a corporate and modern look, giving the impression of providing not only better education but also administrative efficiency. It is also obvious that technology makes formal education possible outside or beyond the walls of universities by widening access for steadily increasing number of students and providing them with more diverse educational opportunities to choose from (Selwyn 2011:26-27). One of the most significant benefits of the need or pressure for the use of technology in education is the opportunity to rethink education and re-imagine the role of all stakeholders in a rapidly changing world, including educational institutions, educators, students and parents.

In the next section, main results of the three empirical studies evaluating the use of technology in formal, structured and self-structured academic contexts are presented. These kinds of studies are crucial because they underscore the ambiguous results of technology whilst pointing to the complex nature of technology as medium. They also refer to the values that technology impose, as well as the choices of the users thereof, informed by personal and societal values.

\section{Technology in the classroom}

The first study wished to establish whether there is a difference in terms of learning outcomes between two groups of first year students in a course on information technology. One group of students made use of Open Educational Resources (OERs) and classroom teaching. They could therefore access the cloud classroom after classes to assist them in their learning process. Open educational resources include text, images, audio, video, interactive simulations, problems and answers, and games that may be freely used and reused in innovative ways by anyone around the world (Ming Chuan \& Ming Chuan 2014:90). The other group received only classroom teaching without access to open learning materials and direction. The PowerPoint skills of the OER group were better than the class taught group, whilst the computing skills of the OER group were lower than the non-OER group. The study concluded that overall there was not a significant difference in the outcomes for two different groups. The researchers accounted for small differences by explaining that in some situations the non-OER group did better than the OER group because the OER group may have been distracted in class and tended to reason that they could learn the formulas and functions later from the online material. The OER group also reported that difficult formulas need class explanation and illustration from teachers, which means that explanations offered in the cloud classroom were insufficient. Moreover, the needs of the students, and their prior knowledge of the course or subject, are important factors that need to be considered when designing a course.

The second study referred to is the first year physiology course in Australia. Researchers Ernst, McGhanand and Harrison (2015) did empirical work to see whether there was a difference in the performance of two groups of students who had different forms of assessments. The first group completed, in small groups, written assignments, whilst the second group of next year students did video assignments, also in small groups. These assignments were formative assessments in preparation for a summative assessment in the form of an examination. The researchers made use of online surveys as well as focus groups after submission of videos and final examination to explore the students' perceptions regarding the video assignment.

The first group that completed written assignments fared much better in examination than the second group that did video assignments. According to students, the video assignment did not help them to prepare for examination. Moreover, it took a lot of time because students were not familiar with the process of making videos, as opposed to those who wrote essays. Unfamiliarity with the process could result in increased labour and stress. It was assumed that video assignments would bring about peer-mediated learning benefits, but that did not happen; more peermediated learning took place in the first group. Many students indicated that they did not watch videos, which partially explained why the form of assessment was of little help in preparing for examination. Some students indicated 
that they did not trust the veracity of peer-generated animations (Ernst et al. 2015:36). What is Interesting is that nearly half of the second group students (i.e. video group) thought that although video assignment was interesting, it did not necessarily lead to positive results.

The final example comes from a master's study carried out with undergraduate students at Stellenbosch University focusing on their digitally mediated learning experiences. This study is of importance because it was conducted at a university in South Africa, and even more important is that it stresses the nature of the medium, as how digitally mediated learning experiences influence the behaviour of media users. Parry (2017) conducted a qualitative study using focus groups to understand the impact of students' use of media in structured and self-regulated academic contexts. Thirty students participated in focus groups and a topic guide was used focusing on what media students use, how (manner) and why (motivation) they use media, the role of social norms in students' behaviour regarding media use, and its impact on academic performance. The most important findings are summarised as follows: Students are aware of the impact of media multitasking on their academic performance; in other words, they know that it is a hindrance to their learning and are aware of the cognitive cost of such behaviour. A direct result of their behaviour is that they have to spend more time to catch up with work outside class towing to their lack of concentration in class. This implies that they behave differently in self-regulated academic environments. Since their peers also share this behaviour, it is viewed as normal in academic environment. It is interesting to note that students restrict this behaviour when doing group work (Parry 2017:60-63).

The question this begs is, whether students are aware of the cost of their behaviour, if so, then why do they continue with the behaviour? Since this behaviour becomes a habit, it is difficult to change. Moreover, students view their attention as a scarce source, which they bestow on a stimulus they deem worthy of it. Most of them said lectures are boring, whilst the media provides them with unlimited entertainment that connects with their desire for stimulation and satisfaction. Engaging with different media forms during a lecture is therefore a form of escape and coping with the current reality (Parry 2017:93-97).

To understand why different forms of new media are so disruptive, we have to pay attention to the characteristics of the medium. One of the central characteristics of digital media is that it is interactive, redefining the role of user from a passive one to an active participant, whilst the accessibility of media makes it difficult to ignore and easier to engage with. The hypertextuality of the media means that different texts are connected and one link can lead the user to several other links that could keep them occupied for several hours. These examples optimistically challenge our sometimes simplistic view(s) of technology as a tool and remind us that how the design is integrated into education is of utmost importance, and more importantly that whilst we often just concentrate on educational technologies, we forget that social media is a major disruptive force not only outside but also inside the classroom.

The next section unpacks the social embeddedness of technology and the forcefulness thereof by discussing mediatisation theory, the technological revolution and the Fourth Industrial Revolution (FIR).

\section{The social embeddedness of technology Mediatisation theory}

Hjarvard (2008), one of the leading scholars on the mediatisation theory, argues that the media acts as an agent for changing culture. According to Couldry and Hepp (2017:32), '...media means technologically based media of communication which includes institutionalised communication'. Hjarvard (2011:122) notes that mediatisation entails that the media develops into an autonomous, independent institution. Part of this autonomous nature is that the media have a logic of its own, which includes affordances, characteristics and modalities whereby the media are operated.

For Hjarvard (2008), and Couldry and Hepp (2017:35), it is important to make a distinction between mediation and mediatisation: 'Mediatisation designates the process through which core elements of social or cultural activity assume media form' (Hjarvard 2008:13), mediation, on the other hand, refers to the process of communication through media whereby the message as well as the sender and receiver is affected. Put differently, mediation focuses on the message and the context in which it takes place; mediatisation describes the long-term effects of the media that lead to social change.

Couldry and Hepp (2017:15) further describe mediatisation as a deep, consistent and self-enforcing role of the media in mediated communication today. The increased presence of the media and how it different forms construct the social world through their communicative affordances are, however, not a role of one media form. Instead, the media operate in clusters, implying that different media forms mutually support one another. Moreover, mediatisation has accelerated over time as explained by Couldry and Hepp (2017:39-51) through waves of mediatisation. At least three waves of mediatisation are identified, namely mechanisation, electrification and digitilisation. Mechanisation includes the invention of factories and railway, whilst electrification involves a move from mechanisation to electrified media such as audiotapes, photography, radio and television.

Digitilisation relates to the internet, computer and mobile phone. These different waves demonstrate that mediatisation needs to be understood in a historical context. Moreover, mediatisation deepens over time through the acceleration of technological innovation in terms of time. The time span 
between the developments of different media forms has become shorter over time, namely the interval between the printing press and the printed newspaper was about 150 years, film, radio and television were invented within the next 50 years, and the various digital media forms within about 30 years (Couldry \& Hepp 2017:53).

Another way of understanding the impact of technology on society is described as technological revolution.

\section{Technological revolution}

Technological revolution describes the enormous social impact the development of technology has on the society. A revolution does not happen all at once but develops over time. Although this may create an impression that there is a gradual development, the future of revolutions is not predictable. Moor (2008:27) identifies three stages that signify technological revolution, namely:

1. introduction stage

2. permeation stage

3. power stage.

During the introduction stage, the implementation of technology is accompanied by curiosity about things regarded as playful. As the device improves, more people become aware of it, but the integration into society is limited or marginal. This is normally because the device is too complex and/or expensive. During the permeation stage, the device becomes standardised, the cost drops and therefore access to the device increases, resulting in more people using the device. Although the integration into society is still moderate, the impact becomes more visible. The power stage signals that the technology is established because it is readily available and people know how to use it as it builds on existing technological structures.

The most important sign that a device has reached the stage of a revolution is the significant impact it has on society. Examples of such devices are automobiles and electricity, because if these were to be removed from society, the impact on society would be massive. Revolutions do not occur overnight but are preceded by a pre-revolutionary period, when an understanding is developed to make the introduction phase possible. Similarly, there is a post-revolutionary phase, which is characterised by a continuous process of establishing of technology or replacing it with a better technology. There is a differentiation between open technology revolutions, meaning that the device is accessible and used by the public, for example computers and mobile phones, and closed revolutions, meaning limited access to technology, such as nuclear weapons.

Sub-revolutions also occur within a technological revolution, implying that many technological developments take place at the same time. Smart phone is an example of a subrevolution embedded within the computer revolution (Moor 2008:29).

\section{The Fourth Industrial Revolution}

Another way of describing the rapidly and continuously changing world facilitated by sophisticated technology is the Fourth Industrial Revolution. The FIR is a buzz word that is often used today, especially in political and economic circles. This, however, does not mean that all of us have a basic understanding of what it means. The following summary given by Schwab and Davis (2018) is fitting to define FIR:

The Fourth Industrial Revolution is a way of describing a set of on-going and impending transformations in the systems that surround us, and which most of us take for granted every day. While it may not feel momentous to those of us experiencing a series of small but significant adjustments to life on a daily basis, it is not a minor change - the Fourth Industrial Revolution is a new chapter in human development... Once again driven by die increasing availability and interaction of a set of extraordinary technologies. (p. 7)

The FIR can be viewed as an extension of the previous discussion of technological revolution, describing a new phase in technological development and the impact thereof on people, society and how we live our lives. Schwab and Davis (2018:4) stress that the FIR is more than a description of technological change; technological innovation is also a powerful driver of wealth and well-being. The FIR has an unmistakable impact on the economy and health, key aspects of human existence. Therefore, one of the main challenges brought about by the FIR is ensuring that its benefits are distributed fairly, as opposed to previous industrial revolutions, when the benefits were not distributed fairly. Furthermore, the unintended consequences need to be managed and efforts need to be made to protect vulnerable populations and the environment in order to create a better world for the future generations. Human agency is another important aspect that needs to be secured in the FIR, because technologies can now intrude on our private spaces such as reading our thoughts and influencing our behaviour (Schwab \& Davis 2018:13-14).

This short summary of the FIR and the accompanying challenges indicate that the impact thereof is not only significantly different but also more serious than those of the previous revolutions. Moreover, it indicates the wide-spread impact it has on society, which warrants continuous critical reflection in order to not only gain some understanding of the world and life it creates but also how it is changing us and our value systems.

\section{Technology and ethics}

In the words of Schwab and Davis (2018):

We need to deepen our understanding of the way the new technologies connect with one another and influence us in both subtle and obvious ways, reflecting and amplifying human values as we make decisions around investment, design, adoption and reinvention. (p. 8)

This means that technology is not value neutral, and our choices regarding the use and development of technology 
reflect our values. This aspect is essential for theological reflection, because the kind of world and life that we are creating addresses one of the core tasks of theological reflection. This is also why Schwab and Davis (2018:29) advocate for a value-based approach to engage with the complex and rapidly changing technological environment. Such an approach needs to be informed with a more nuanced perspective of technology, namely that technology and society shape each other. Therefore, positive, unintended and negative outcomes caused by technology cannot be blamed only on technology but we also need to take co-responsibility. The question begs how we can take co-responsibility for the changes caused by technology. Schwab and Davis (2018:34) suggest that we accept the following three responsibilities:

1. identify the values that are embedded in certain technologies

2. determine how technologies impact our choices and decision-making

3. decide how to influence technological development in collaboration with relevant stakeholders.

These suggestions imply that we know what our societal values are, but is that really the case? How do we create and sustain spaces that confront and empower people across cultural and generational lines to take up their responsibility to formulate and embody shared values? This is undoubtedly not an easy task in a pluralistic world, where diversity is a distinctive feature. However, this is one of the most urgent challenges and opportunities that the FIR presents us. Although we may feel overwhelmed by the rapid changes brought about by technology, we should not withdraw into passivity, but we should identify our responsibility as of cocreators of this change.

Moor (2008:34) notes that the technological revolution generates several ethical problems, because as new technologies emerge, we may be faced with previously unknown ethical dilemmas. This implies that we may find ourselves in a conceptual and policy vacuum. In other words, we may be faced with situations where we do not have the vocabulary to describe the ethical problems at hand nor have policies in place to address them. The worse is the scarcity of people having knowledge of technology and ethics. Therefore, it is suggested that the best way of engaging with this situation is to put more effort into ethical reflection during the design phase of technology.

Who are the main actors in the design and development of technology? Although the users also have an indirect effect on this process, a smaller group of engineers, economists and politicians are the main role-players making decisions regarding the design of technology. Hersh (2014) wrote an insightful article on how we can promote ethics and social responsibility amongst engineers as key role-players in the design and development of technology. These suggestions are found helpful for a broader audience, as these principles inform us about the process of taking co-responsibility for the world we are creating through technology. To understand the power of technology, we need to understand the power of existing economic and political powers that play a central role in decision-making around the design and the use of technology, and in whose interest it is developed. Technological development is embedded within existing structures of power and society, and therefore ethics needs to be a central aspect of education today. If we leave this task to people in positions of power, inequality and ecological crisis would worsen. These power structures could prevent ethical conduct of engineers and other professionals (Hersh 2014:168). Unethical activities may be legal and profitable, and therefore hard to resist.

An empirical study carried out by Hersh (2014:170) indicates that the lack of ethics in organisations and the broader society has a tremendous effect on how individuals act when faced with situations where they have to make ethical decisions. In order to overcome some of the challenges of cultivating ethical behaviour and determining what is ethical, Hersh (2014:172) argues that it is necessary to consider the perspective of 'other'. He identifies 'other' as the marginalised, minority group and the environment (Hersh 2014:167). Such a broader consultation and perspective has the common good in mind, rather than just serving the interests of the powerful. We often work with a narrow perspective that prioritises the interests and the needs of people whom we identify with, therefore the engagement with the other is pivotal to gain a broader perspective of what is at stake when making certain decisions. Such a process, however, can be complex and takes time, something that the fast moving and changing society created by technology often does not have. Useful questions to consider in this process are how technology would affect the local community and culture; whose interests would it serve and what would be the impact on the environment? The engagement with the other requires willingness to consider the perspective of the other and should prioritise meaningful engagement where listening allows for the genuine exchange of ideas and experience (Hersh 2014:172). Therefore, a top-down approach to ethics is not a viable option. Such engagement asks for an inclusive approach in which not only those in power are consulted but the input of those on the margins is also valued and incorporated to enhance co-responsibility and creditworthy development.

As mentioned above, technology is not value neutral, instead it promotes instrumental values such as functionality, efficiency, safety, reliability and ease of use (Flagan, Howe \& Nisssenbaum 2008:322).

Moreover, technology tends to impose its encoded values on society. Technology is also received by people who exercise certain values when using it. Gunderson (2017) revisits Max Scheler's studies on values to indicate how societal values shifted because of technological development. In summary, Scheler ([1913] [1916] 1973) focuses on the relationship between technology, values and the environment. Scheler postulates the existence of value ranking in society. In other 
words, there is a priority list of values in society that can be summarised as follows: (1) Values of the holy and the unholy (feelings of blissfulness and despair); (2) spiritual values (values of the mind, aesthetics, juridical and philosophy); (3) vital values (viability and ineptitude); (4) sensible or pleasure values and (5) utility or pragmatic values (values of usefulness and non-usefulness) (Gunderson 2017:404). The values that top this ranking list change from time to time to time. In a technologic age, technological artefacts are conceptualised as bearers of utility values that should bring happiness and expand life (Gunderson 2017:406). Not only does this change in values subordinate the values of life but it also indicates the role of technology in society as the machine dominates life.

In his thought provoking, book Homo Deus: A brief History of tomorrow, Harari (2016) unpacks in detail how technology informs the human agenda from a historical perspective. His account of how developments throughout history always brought about changes in people's value systems is remarkable. Harari (2016:3) poses the question '...given the immense power that biotechnology and information technology are providing us with, what will we do with all that power?' Harari (2016:23-24) contends that since human beings always crave for more, they are continuously on the lookout for something that is better and bigger. In the light of this understanding of humans and the availability of advanced technology, the human agenda is prioritising happiness, immortality and divinity as key objectives. Realities such as death and unhappiness are viewed as technical problems for which technical solutions should be found. Such projects have the support of science and the capitalist economy, provided they lead to new discoveries and profits (Harari 2016:32).

According to science, both happiness and immortality are dependent on biochemical systems, and therefore to ensure both, all that is needed is to manipulate biochemistry (Harari 2016:47). These three values are interrelated since a dead person cannot experience happiness, thus immortality becomes an important objective.

Harari (2016:49) contends that another way of understanding and describing this project is that humans wish to upgrade themselves into gods. He defines the centring of humans to replace the gods of Christianity and Islam as humanism. According to humanism, the human experience is the ultimate source of meaning-making. Dataism follows humanism, declaring that the flow and processing of data is the most important task. The religion of dataism proclaims that humans and their experiences are not sacred but merely tools that create the internet-of-all-things (IoT) present everywhere and controls everything (Harari 2016:444).

According to Harari (2016:452), 'Dataism adopts a strictly functional approach to humanity, appraising the value of human experience according to their function in data processing mechanisms'. Furthermore, the religion of dataism declares humans as outdated technology and has one mission - to convince that all flow of data is good, and blocking it is $\sin$.

Harari (2016) names at least two important developments that could be viewed as contradictions or a fail of plan as far as the human agenda is concerned. Firstly, the more the knowledge is created through science, the faster the change occurs, which in turn makes the knowledge irrelevant. Put differently, the more knowledge we have, the less we can predict the future. Secondly, the upgrading of humans to gods may lead them becoming irrelevant too (Harari 2016:422). Although what Harari puts on the table may not happen overnight, the current human agenda needs urgent intervention, otherwise humans could be reduced to mere extensions of technology in the near future.

\section{Conclusion}

In conclusion, a few remarks and pragmatic suggestions are made for education in general, and a few questions are posed that could inform our theological research in particular.

We are often stuck with the use of technology to facilitate the process of education with little or no critical reflection on what technology entails. As per the examples provided in the article, the integration of technology does not necessarily yield convincing evidence of making any significant difference in terms of learning outcomes. There should rather be more focus on the designing of these activities by technology and gaining a better understanding of the nature of educational technologies. These are often not as interactive as other forms of media, using a top-down approach that focuses on content instead of people. It also provides little or no interaction outside the classroom (Pereira, Baranauskas \& Da Silva 2013:6).

There is sometimes too much focus on what happens inside classrooms in structured forms of learning and too little on the informal learning and experiences of students outside these spaces. Often information gathered outside structured academic spaces has more impact on the learning process than structured classroom teaching. Therefore, we need to find ways to access this knowledge and experiences in responsible and creative ways, as that would bring the lifeworld of students into the classroom.

Knowledge in the form of information can no longer be all that we are offering. We need to introduce complexity to students in a helpful way, since an important skill in the future would be the ability to cope with not knowing in a world that is changing faster than we could account for in our research. Interpretation skills and the ability to form a picture (synthesis) from all bits of information would be the key. Therefore, creative ways need to be developed to not only test student's cognitive capabilities but also other much-needed capabilities such as flexibility. Another 
important element to survive in a rapidly changing world is emotional stability, something many students struggle with for different reasons. Since the world is changing so fast that there are no authentic script and the students would need skills to reinvent themselves continuously as they navigate their way through life.

The discussion on the invasive and persistent nature of technology has made it clear that cultural analysis is a critical skill to develop a sense of important issues. This, of course, implies another important skill, namely to know what to ignore. Do our students follow courses that primarily focus on theological subjects, equipped well enough to interpret the world they live in? Would it not be more helpful if students are also introduced to subjects such as culture and media studies, sociology and psychology, because these could put forward the most pressing questions of the day? Are theological subjects providing students with the necessary vocabulary and insight about humans and the world they are living in?

We are at a crossroad where we could still make ethical decisions to turn the tide of runaway technological development that could potentially reduce humans to mere extensions of the technological revolution. The direction we take from here would have far-reaching implications, especially for the next generations and the world we leave behind for them. A few questions are posed below that could inform research in theology and technology:

- Is our current theology, and especially ethics, geared towards giving us guidance in the technological age?

- Are we paying enough attention to what values are driving technological developments?

- What does it mean to be human in a theological age?

- What does bodied human life mean?

- Does our theology assist or allow us to celebrate and critique human labour at the same time?

- Are we open to critique of our sometimes-limited and instable theological frameworks by these technological developments?

Academic institutions have the responsibility to be forward thinking, even more so in a time when it seems to be an impossible task. This does not mean that we should be able to predict the future, but theology should be able to draw on its normative sources whilst engaging with other sciences in a creative way. Multidisciplinary research should be a key focus to ensure that our fate is not in the hands of genetic technology, nanotechnology and neurotechnology. The train of technological development might not have started out fast, but definitely it would pick up speed over time and is urgently in need of ethical direction, and it is believed that theology has a significant role to play in responding to this call(ing).

It became clear that technology is at the centre throughout different eras of development as described by the technological revolution and the FIR. The mediatisation theory helped us to gain some understanding of how consistent and deep is the impact of technology on human life and on the world we are living in. In light of the consistent and deep impact of technology, it is safe to argue that technological development is unstoppable. However, in the movie Unstoppable (2010), two partners that never worked together manage to get the runaway train under control. When we think of technological development, religion and theology are not the first disciplines that come to our mind, but just like in the movie, these disciplines should get on board to give guidance in terms of ethical considerations regarding the design of technological development and the values it promotes. The persistent impact of the technological revolution on the relationship between the human and the divine is also noteworthy and needs much more attention from a theological perspective. More important is the disaster of inequality, identified as the most urgent challenge of the FIR. Inequality needs to be countered with values that promote justice for people and the environment.

\section{Acknowledgements Competing interests}

The author declares that they have no financial or personal relationships which may have inappropriately influenced them in writing this article.

\section{Author's contributions}

A.L.C. is the sole author of this research article.

\section{Ethical considerations}

This article followed all ethical standards for a research without direct contact with human or animal subjects.

\section{Funding information}

No funding was used for this research.

\section{References}

Cloete, A., 2017, 'Technology and education: Challenges and opportunities', HTS Theological Studies 73(4), 1-7. https://doi.org/10.4102/hts.v73i4.4589

Couldry, N. \& Hepp, A., 2017, The mediated construction of reality, Polity Press, Cambridge.

Ernst, H., McGahan, W.T. \& Harrison, J., 2015, 'Questionable benefit of visual and peer mediated learning on the overall learning outcomes of a first-year physiology course', International Journal of Mobile and Blended Learning 7(1), 25-40. https://doi.org/10.4018/ijmbl.2015010103

Flagan, M., Howe, D.C. \& Nisssenbaum, H., 2008, 'Embodying values in technology: Theory and practice', in J. Van Den Hoven \& J. Weckert (eds.), Information technology and moral philosophy, pp. 322-353, Cambridge University Press, Cambridge.

Gunderson, R., 2017, 'Environmental knowledge, technology, and values: Reconstructing Max Shelers's phenomenological environmental sociology', Human Studies 40, 401-419. https://doi.org/10.1007/s10746-017-9439-3

Harari, Y.N., 2016, Homo Deus: A brief history of tomorrow, Harvill Secker, London.

Hersh, M., 2014, 'Science, technology and values; Promoting ethics and social responsibility', Al \& Society 29, 167-183. https://doi.org/10.1007/s00146-0130473-z

Hjarvard, S., 2008, 'The mediatisation of religion: A theory of media as agents of religious change', Northern Light 6, 9-26. https://doi.org/10.1386/ nl.6.1.9_1 
Hjarvard, S., 2011, 'The mediatization of religion: Theorizing religion, media and socia change', Culture and Religion: An Interdisciplinary Journal 12(2), 119-135. http:// dx.doi.org/10.1080/14755610.2011.579719

Ming Chuan, C. \& Ming Chuan, P., 2014, 'Do open educational resources and cloud classrooms really improve students' learning?', International Journal of Information and Communication Technology Education 10(1), 89-96. https://doi. org/10.4018/ijicte.2014010108

Moor, J.H., 2008, 'Why we need better ethics for emerging technologies', in J. Van Den Hoven \& J. Weckert (eds.), Information technology and mora philosophy, pp. 26-38, Cambridge University Press, Cambridge.

Parry, D.A., 2017, 'The digitally mediated study experiences of undergraduate students in South Africa', Master's of Arts in Socio-Informatics thesis, Stellenbosch University, Stellenbosch.
Pereira, R., Baranauskas, M.C. \& Da Silva, S.R., 2013, 'Social software and educational technology: Informal, formal and technical values', Educational Technology \& Society 16(1), 4-14.

Scheler, M., [1913] [1916] 1973, Formalism in ethics and non-formal ethics of values: A new attempt toward the foundation of an ethical personalism, Northwestern University Press, Evanston, IL.

Schwab, K. \& Davis, N., 2019, Shaping the Fourth Industrial Revolution, World Economic Forum, Geneva.

Selwyn, N., 2011, Education and technology: Key issues and debates, Continuum International, London.

Unstoppable, 2010, Motion picture, Westwood, Los Angeles, CA, produced by Tony Scott. 